\title{
NE TRAVAILLEZ JAMAIS, OU DA CRÍTICA AOS PROCESSOS FORMATIVOS DO CAPITALISMO E SUAS CONSEQUÊNCIAS
}

Roberto Rondon ${ }^{1}$

\section{Resumo}

A pergunta sobre a qual queremos refletir nesse artigo é sobre os desafios colocados para a educação num tempo de crise global do modelo civilizatório da sociedade do trabalho. Guerra, violência urbana, desemprego, crise hídrica, corrupção, enfim, precarização e destruição da vida são algumas das notícias espetacularizadas que nos cercam todos os dias, sem que consigamos fazer a ligação de todos esses aspectos como consequências necessárias da lógica do trabalho capitalista. Amparados nas percepções de Marcuse, e de De Grazia, pretendemos abordar as possibilidades da crítica aos princípios formativos dessa sociedade, como forma de abrir novas possibilidades para a formação humana.

Palavras-chave: Educação, Trabalho, Ócio

\section{Resumen}

La pregunta sobre la que queremos reflexionar en este artículo es acerca de los desafíos puestos para la educación en tiempos de crisis global del modelo civilizatorio de la sociedad del trabajo. Guerra, violencia urbana, desempleo, crisis hídrica, corrupción, en fin, precarización y destrucción de la vida son algunas de las noticias vehiculadas a diario de modo espectacular que nos cercan sin que logremos hacer el vínculo de todos estos aspectos como consecuencias necesarias de la lógica del trabajo capitalista. Amparados en las percepciones de Marcuse y de De Grazia, pretendemos abordar las posibilidades de la crítica a los principios formadores de esa sociedad como forma de abrir nuevas posibilidades para la formación humana.

Palavras chave: Educação, Trabalho, Ocio

as coisas mais belas são as que não existem"

Manoel de Barros

A incapacidade quotidiana de pensarmos alternativas radicais para a educação, além das palavras e mandamentos exaustivamente repetidos a toda hora e em todos os lugares por aqueles que organizam e reproduzem as práticas $e$ discursos sobre o ensino brasileiro dentro da ordenação do mundo do trabalho, parece nos levar a uma rua sem saída, onde percebemos que estamos no caminho errado, mas já não temos ânimo, nem forças para imaginarmos outras rotas.

\footnotetext{
${ }^{1}$ Professor Adjunto da Universidade Federal da Paraíba. E-mail: rondon.roberto@uol.com.br
}

RONDON, Roberto. Ne travaillez jamais, ou da crítica aos processos formativos do capitalismo e suas consequências. Revista Sul-Americana de Filosofia e Educação. Número 24: maio-out/2015, p. 254-269. 
O que nos preocupa aqui é essa perda constante da capacidade de pensar diferente, em espaços que cada vez menos permitem a construção de sentimentos que contrastem com a acelerada e, cada vez mais rápida, busca da adequação à sociedade do trabalho e da produção.

Que mágica foi essa que encantou os homens e mulheres de nossa sociedade a partir do final do século XIX, justamente quando os processos de reprodução da vida alcançaram tal grau que a produção mundial, desde a década de 1960, tornando-se suficiente para atender a necessidade global?

No entanto, a lógica da necessidade permanece e em todos os cantos do país se ouvem nas filas dos desesperados: "Mais trabalho, mais trabalho!". Pois através dele se espera recuperar, não as condições de sobrevivência material - pois com os salários e as jornadas da massa dos trabalhadores brasileiros essa afirmação seria falaciosa -, mas as condições de dignidade social.

Aliás, só como curiosidade, não encontramos o conceito de erotismo em nenhum plano de ensino de nenhuma instituição de ensino por que passamos em nossa vida. Apenas "habilidades", "competências", "cultura empreendedora", "razão", "ética”, "cidadania", "pensamento crítico", etc.

Mais ainda, se pudéssemos elaborar uma escala decrescente que vá de cem a zero e tomarmos a educação infantil como ponto 100 de uma educação centrada no lúdico, com quantos pontos chegaríamos aos currículos de graduação e pósgraduação?

Forma-se a "bola de neve", professores mutilados, formando alunos erótico e esteticamente - deficientes, cujo único vislumbre de liberdade é o sinal da hora do recreio.

Mas, os defensores da "educação para o trabalho" poderão dizer que hoje uma das grandes preocupações desta é a preparação de trabalhadores que sejam profissionais criativos, sensíveis e que valorizem os aspectos lúdicos. A falácia desse discurso é que as premissas invalidam a continuidade do raciocínio, ou seja, a criatividade, a sensibilidade e o lúdico, são pressupostos não de um desenvolvimento pleno dos humanos como tal, mas dos trabalhadores $e$ profissionais exigidos pelo "novo" mercado. 
Tudo isso em nome de que?

A resposta parece fácil. Estamos numa etapa do desenvolvimento, necessária para atingirmos uma sociedade mais justa e feliz. Sofremos agora, mas nos regozijaremos depois, é a eterna promessa.

Mas que sociedade é essa que nos prometem, ou melhor, que grande parte das pessoas busca?

Marcuse (1970b, p. 133), já no final dos anos 1960 se perguntava qual o papel do indivíduo na tal "Grande Sociedade" 2 . Retomando os discursos oficiais do final dos anos 60 nos Estados Unidos, identificava as seguintes características nos discursos oficiais: uma sociedade de "desenvolvimento ilimitado, fundada sobre a abundância e sobre a liberdade para todos"; com o "fim da miséria e da injustiça racial; na qual o progresso é servo de nossas necessidades"; onde "o tempo livre é uma agradável ocasião para construir e refletir”. Porém, mesmo nesse momento não "haveremos chegado ao fim da luta", pois a sua manutenção "é um desafio constante", "onde o significado de nossa vida acompanha os maravilhosos produtos de nosso trabalho."

Se compararmos essas palavras de mais de 40 anos atrás, com os discursos de nossos atuais políticos, empresários, sindicalistas e "gestores educacionais" veremos poucas mudanças. Crescer, desenvolver, progredir são as palavras de ordem apregoadas até hoje para os corações, mentes e corpos de todas as pessoas.

O filósofo alemão prossegue indagando o "porque" nessa sociedade o significado de nossa vida deveria acompanhar os produtos do trabalho e não o contrário. "Por que a Grande e Livre Sociedade não deveria ser um lugar de repouso, um porto tranqüilo?"

Para ele, já naquela época, com as conquistas tecnológicas e o ritmo de produção atingido era possível atingir aquele porto seguro. No entanto isso não acontecia devido a "uma miséria criada cada vez mais artificialmente", com a produção constante de novas necessidades, tornando obsoletos, numa velocidade alucinante, nossos objetos de desejo passados. Ora, mais do que uma utopia, "a

\footnotetext{
${ }^{2}$ Usamos aqui a imagem da "Grande Sociedade" como alusão às "Sociedades Desenvolvidas", modelo perseguido pelos governos de direita e de esquerda em todo mundo. Marcuse retira essa expressão de um programa do presidente norteamericano Lyndon Johnson.
} 
Grande Sociedade aparece como a continuação direta e reforçada da sociedade existente." (MARCUSE 1970b, p. 135)

Importante ressaltar que as críticas do autor referiam-se tanto às sociedades capitalistas, quanto às experiências socialistas então existentes que, nesse ponto, coincidiam plenamente. Tanto fazia a terra da liberdade yankee como a pátria socialista dos proletários, o caminho era o mesmo: progresso e desenvolvimento.

$\mathrm{Na}$ prática, a terra prometida do desenvolvimento gerou uma "nova escravidão no mundo do trabalho", por que já não produzimos por uma necessidade básica, mas simplesmente para alimentar essa "produtividade repressiva", isto é, trabalhamos para alimentar a necessidade de continuar trabalhando.

Vaneigem (1978), anos depois, elabora a seguinte questão: "Tem sentido, ao menos uma vez, o desejo de chegar tarde ao trabalho ou de abandonálo antes da hora?" Ele mesmo responde que "em tal caso entendemos que":

a) O tempo de trabalho conta em dobro, pois é tempo perdido duas vezes:

- como tempo que seria mais agradável empregar no amor, no sonho, nos prazeres, nas paixões; como tempo do qual dispor livremente.

- como tempo de desgaste físico e nervoso.

b) O tempo de trabalho absorve a maior parte da vida, pois determina a si mesmo o tempo chamado "livre", o tempo de dormir, de deslocamento, de comer, de distração. Afeta também ao conjunto da vida cotidiana de cada qual e tende a reduzi-la a uma sucessão de instantes e de lugares, que têm em comum a mesma repetição vazia, a mesma ausência crescente de vida autêntica.

c) O tempo de trabalho forçado é uma mercadoria. Em todas as partes onde há mercadoria, há trabalho forçado: produzimos, consumimos, comemos, dormimos para um patrão, para um chefe, para o Estado, para o sistema da mercadoria generalizada.

\section{d) TRABALHAR É VIVER MENOS ${ }^{3}$.}

O que resta então do indivíduo? Diríamos sem medo de errar: "Muito pouco". Ele se "converte na unidade da nova sociedade e no espírito do

\footnotetext{
${ }^{3}$ Destaque nosso.
} 
capitalismo, como responsável da iniciativa econômica privada." (MARCUSE, 1970b, p. 145)

Como já havia mencionado em outra obra:

Se a sociedade não pode usar a sua crescente produtividade para reduzir a repressão (pois tal uso subverteria a hierarquia do status quo), então a produtividade deve ser voltada contra os indivíduos; torna-se um instrumento de controle universal. (MARCUSE, 1968, p. 94)

Portanto, acreditamos que uma educação que busque estar "contra a lei do presente" deveria buscar sobre outras bases seus fundamentos.

A educação que aqui pensamos, talvez possível de comunicar algo contra o presente, está baseada na formação de "amadores" no seu mais amplo sentido dos que não são apenas profissionais, mas também daqueles que têm mais desenvolvida as capacidades lúdicas e eróticas.

Não porque sonhemos com uma nova sociedade que venha num futuro distante, mas, como afirmamos anteriormente, devido às próprias condições que a "sociedade do trabalho" proporcionou. Se o modelo de nossa "evolução" social se baseou no conceito de "produtividade", é a partir das próprias conquistas dessa mesma "produtividade", que podemos superar o atual modelo civilizatório. A partir de agora.

A desculpa da escassez, que tem justificado a repressão institucionalizada desde o seu início, enfraquece à medida que o conhecimento e controle do homem sobre a natureza promovem os meios de satisfação das necessidades humanas com um mínimo de esforço. O empobrecimento ainda dominante em vastas regiões do mundo deixou de ser devido, principalmente, a pobreza dos recursos humanos e naturais e decorre, sobretudo da maneira como são distribuídos e utilizados. (MARCUSE, 1968, p. 94)

É preciso então, inverter essa ordem e buscarmos construir a formação humana sobre outras premissas e não mais as desenvolvidas nas últimas décadas. No Brasil, talvez tenhamos uma vantagem, pois como a lógica do trabalho só

\footnotetext{
4 "Essa idéia - produtividade - talvez expresse mais do que qualquer outra a atitude existencial na civilização industrial...O homem é avaliado de acordo com a sua capacidade de realizar, aumentar e melhorar as coisas socialmente úteis... A eficiência e a repressão convergem: elevar a produtividade da mão-de-obra é o sacrossanto ideal do capitalista e do stakhanovismo stalinista." (MARCUSE, 1968, p.143)
} 
começou a ser imposta a partir do final do século XIX, ainda tenhamos mais condições de romper com ela do que nossos protestantes irmãos do norte.

Retomando uma pergunta que elaboramos há uma década atrás, indagamos novamente: "Porque o trabalho e não a arte como princípio formativo de nossa sociedade?" 5

Não é nosso objetivo aqui elaborar uma discussão que penetre nos infinitos labirintos do que são a Arte e o artista, pois isso demandaria um outro estudo. Nos limites desse ensaio nos interessa pensar a arte na sociedade do trabalho, onde constitui-se dentro dos ideais de um saber "autônomo e desinteressado", inaugurando uma tradição que a mantém como uma sombra inútil, nas luzes produtivas e aceleradas da sociedade contemporânea.

Diria o poeta que a arte imita a vida... Se isso é verdade, poderíamos discutir a afirmação de Buckhardt de que "o valor que um povo confere ao trabalho é determinado pelas condições em que desenvolveu seu ideal de vida particular." (apud HAUSER , 2000, p. 117)

Mas, independentemente da conceituação da arte, ao olharmos para as manifestações cotidianas de nosso tempo, percebemos que mesmo os mais standartizados hits da indústria cultural contemporânea, só atingem seus objetivos por apresentarem um mundo "utópico" onde há o final feliz, o amor apaixonado, o gozo, a liberdade, o não trabalho, enfim, situações difíceis de encontrar na dura existência cotidiana de trabalho, trabalho, trabalho. No romance lido às pressas num ônibus a caminho do trabalho, ou numa canção que balança o corpo do jovem "boy" que circula pelas cidades e que o retira, mesmo que ilusoriamente, de seu cotidiano e o conforta, há a possibilidade da fantasia e do afastamento do trabalho. Claro que não negamos com isso o caráter conservador dessa forma de expressão, pois ela acaba funcionando como um "analgésico" para as dores do mundo, sem atacar as causas principais e, o que é pior, nos mantendo nessa

\footnotetext{
${ }^{5}$ RONDON, R. "Por que o trabalho e não antes a arte?" Revista Sul Americana de Filosofia e Educação, no. 2, 2004. Disponível em: http://periodicos.unb.br/index.php/resafe/issue/view/615. Acesso em 01/10/2015.
} 
realidade miserável. Mas, o que não podemos deixar de destacar aqui é o poder mesmo da mais paupérrima expressão estética ${ }^{6}$.

Como afirma Hauser (2000, p. 674): "Toda e qualquer obra de arte é uma visão e uma legenda da realidade, toda arte substitui a vida real por uma Utopia."

Nesse mesmo sentido, Marcuse (1970a, p. 191) considera que: "a arte é uma ilusão: apresenta como existente o que não é. Portanto a arte é agradável; procura uma gratificação substitutiva dentro da realidade miserável."

A dimensão artística talvez tenha preservado, desde o romantismo, uma esfera de liberdade frente à sociedade do trabalho, inclusive contrapondo-se a ela por diversas vezes.

A separação da arte do processo da produção material deu-lhe a possibilidade de desmistificar a realidade produzida neste processo. A arte desafia o monopólio da realidade estabelecida em determinar o que é real e fá-lo criando um mundo fictício que, no entanto 'é mais real que a própria realidade. (MARCUSE, 1977, p. 33)

Mais ainda, a própria figura do artista reveste-se de um "que" de desprezo e admiração. Alguém de quem compramos seus produtos e invejamos sua liberdade, mas quem os "ditos cidadãos respeitáveis", não gostariam de ter como genros ${ }^{7}$.

Marcuse (1970b, p. 148) retoma a figura do "poeta maldito" para exemplificar a posição de alguém que ousa afirmar sua individualidade e que, portanto, é um opositor do sistema.

Este vive efetivamente sua vida: à margem da sociedade e contra ela. $\mathrm{O}$ indivíduo se volta autêntico na medida em que está excluído, dedicado às drogas, enfermo8, genial. Parte desta autenticidade se mantém ainda no boêmio, inclusive no beatnik. Representam manifestações de liberdade e de alegria individual, de alguma forma protegidas $e$ defendidas, e que não agradam ao cidadão comum, o qual define a

\footnotetext{
${ }^{6}$ Philip Roth, através de seu personagem David Kepesh, vai mais longe ao citar o exemplo da pornografia: "É uma forma de arte degradada. Não é apenas faz-de-conta, é uma coisa abertamente insincera. A gente deseja a garota do filme pornô, mas não sente ciúme do sujeito que a está comendo porque ele age como substituto da gente. É extraordinário - para você ver o poder da arte, mesmo degradada."(p.40) Roth, P. "O animal agonizante". São Paulo: Companhia das Letras, 2006

${ }^{7}$ Não só o artista, mas a própria arte, como afirma Marcuse (1973, p. 97): "Apesar do seu uso (feudal e burguês) como símbolo de status, consumo conspícuo e refinamento, a arte conserva aquela alienação da realidade estabelecida que está na origem da arte."

8 Para Hauser $(2000,680)$, "a enfermidade romântica é, uma vez mais, somente uma fuga ao domínio racional dos problemas da vida, e estar enfermo não passa de um pretexto para afastar-se das obrigações da rotina cotidiana."
} 
liberdade e a felicidade com os termos do governo e da sociedade antes que com seus próprios.

Obviamente que se penetrarmos no mundo da "grande arte", aí a separação é mais radical, pois ela exige atenção, concentração, silêncio, ou os "movimentos" mais difíceis na sociedade contemporânea: Parar e calar.

Numa sociedade na qual se corre para lá e para cá, para "ganhar" a vida, para cuidar da saúde, para realizar as tarefas num tempo cada vez mais curto, onde expressões como "tô na correria", "não pode parar, né!", ou a clássica "cabeça parada é oficina do demônio", o tempo parado para apreciação de uma obra de arte requer uma revolução profunda na "condição humana" contemporânea. Além disso, a contemplação no silêncio é quase que intolerável na sociedade do trabalho. A lógica do correr com o barulho tem seu maior exemplo no corredor de "Iphone" pelos já nem tão "silenciosos" parques... Mas, não só. Liga-se a TV e o som ao se chegar em casa; carros desfilam pelas ruas com alto falantes ligados na última potência; os bares são invadidos por milhares de decibéis; fala-se sobre tudo e a todo momento; grita-se (mas quase sempre sem ninguém ouvir), o guia exasperado pede "silêncio" aos turistas nos passeios ecológicos, porque o barulho espanta os animais; a rapidez e o barulho movem as pessoas que passam pelas obras nas exposições de artes plásticas onde o mais importante é o selfie ao lado da obra, ou ainda, o eterno, e desrespeitado, pedido de "desliguem os celulares" durante as apresentações musicais, peças de teatro, ou cinemas, tornam o "parar" e "calar" quase utópicos, não sendo possível calar os "trabalhadores" contemporâneos que não conseguem se deparar com a própria vida.

Note-se que nas escolas e faculdades mais "moderninhas", são instalados sistemas de som ambiente, assumindo a impossibilidade do silêncio mesmo no "ambiente".

Mas isso é o pressuposto da arte. Nas palavras de Marcuse (1973, p. 104): "Existe um evento simbólico que anuncia transição da vida cotidiana para um meio essencialmente diferente, o 'salto' do universo social estabelecido para o universo da arte: é a ocorrência do silêncio" 
Poderíamos pensar que numa sociedade miserável é impensável cobrar isso das pessoas, mas aqui não nos referimos a essa parcela majoritária de nossa população. Para essa o trabalho (ou a luta pela procura dele) se incumbe cotidianamente de brutalizar. Falo dos que já superaram essa linha, os favoritos que podem "consumir" esses produtos. O homem (ou a mulher) parados em frente a um quadro no meio da turba, o simples apreciador da arte (não o marchand à caça de algum produto) são sempre vistos ou como pessoas sensíveis, ou esquisitas, pelos "corredores barulhentos", mas nunca como um "deles", ou seja, alguém normal nesse mundo.

Portanto, acreditamos que a arte, muito mais do que nos ensinar apenas novos conteúdos ou conceitos, é uma atividade política. Não que estejamos dentre aqueles que acham que a arte torna as pessoas eticamente melhores. Longe disso, apenas pensamos que elas se tornam esteticamente mais completas, seres humanos com uma maior amplitude de experiências do que o "realismo" das atividades reunidas sobre o conceito de trabalho pode oferecer. Educar pela e para a arte é libertar o impulso lúdico que tem "por objetivo a beleza e por finalidade a liberdade." (MARCUSE, 1968, p. 166)

Parar, silenciar, contemplar. Não seriam esses também os ideais do homem ocioso?

Não falamos aqui dessas novas concepções do "ócio criativo" e da "pedagogia do ócio", que, a nosso ver, não rompem com a estrutura básica do problema aqui abordado, pelo contrário, continuam fazendo a roda andar. Ambas as concepções partem do pressuposto que nesses novos tempos estamos constituindo uma sociedade com mais tempo livre e que, por isso teríamos que ter o que eles chamam de ócio, como algo integrado às preocupações dessa sociedade. Não apregoam uma ruptura com a "sociedade do trabalho", mas simplesmente tentam responder sobre o que fazer com o tempo livre, dentro da lógica da produtividade e que, talvez por isso, tem feito tanto sucesso nas empresas e nas escolas, se é que ainda há tanta diferença entre essas. 
Como "confessa" o próprio Domenico de Masi, em entrevista: "Quando uma empresa inaugura um modelo organizacional baseado em minhas idéias, ganha muito mais e os seus trabalhadores são muito mais felizes" ${ }^{9}$

E conclui: "Eu não gosto do ócio puro: depois de um pouco de tempo, me aborrece. Eu gosto do ócio "criativo": isto é, a síntese do trabalho, do estudo e da diversão ${ }^{10}$. O ócio criativo nunca me aborrece."

Luccy (1995), num texto para professores do ensino médio em defesa do "ócio criativo", reforça essa separação entre a nova concepção do "ócio criativo" e o "ócio", ao afirmar que essa nova expressão "que vem fazendo sucesso hoje[...] na verdade não é ócio, até pelo contrário" é um momento em que "devem fertilizar novas idéias, novas visões para nossas vidas e as vidas das demais pessoas e nações". Portanto, "o ócio criativo é a única forma de produzir idéias geniais. Idéias geniais vem apenas com o ócio criativo através de uma atividade que consiga unir aprendizagem, trabalho e alegria".

Bem, se os próprios divulgadores da proposta dizem que ócio criativo não é ócio e que se entediam com ele, não podemos acompanhá-los em nosso estudo.

Os mesmo problemas encontramos nas propostas da nova "pedagogia do ócio". Desenvolvida em alguns países da Europa, encontramos uma extensa bibliografia composta por livros e artigos sobre o tema.

Tomamos como guia de nossa reflexão o livro "Pedagogia do Ocio" de Manuel Cuenca Cabeza. A obra apresenta uma ampla quantidade de considerações sobre o Ocio, incluindo conceituações teóricas e a narrativa de experiências práticas de algumas insituições educacionais espanholas. O texto se desenrola justificando a importância do Ocio frente às novas realidades da sociedade vigente, ressaltando seu papel de construtor de novos valores e atitudes.

Ainda que apresentem uma grande quantidade de conceitos sobre o Ocio, ele aparece sempre numa lógica da criatividade, do desenvolvimento dos

\footnotetext{
9 Entrevista concedida ao consultor empresarial Mário Persona, disponível no site www.mariopedrosa.com.br. Acesso em 01/10/2015.

10 No site da Editora Sextante, podemos ler no tópico de apresentação do autor: "A movimentada biografia desse autor deixa claro, através de sua história pessoal, que ócio criativo não significa indolência”. Disponível em www.exestante.com.br. Acesso em 01/10/2015.

${ }^{11}$ Destaques nossos.
} 
potenciais humanos e, como afirma o documento do Conselho da "World Leisure $^{12} \&$ Recreation Asociaton", citado por Cabeza (1995, p. 25), um importante aliado na lógica do mercado. Em seu artigo $2^{\circ}$. Considera que:

O Ocio é um recurso importante para o desenvolvimento pessoal, social e econômico e é um aspecto importante da qualidade de vida. O Ocio é também uma indústria cultural que cria emprego, bens e serviços. Os fatores políticos, econômicos, sociais, culturais e ambientais podem aumentar ou dificultar o Ocio.

Essa necessidade constante em justificar o Ocio como um fator "produtivo" na sociedade atual, a defesa da integralidade entre trabalho e Ocio, a insistência em apresentá-lo como construtor de valores, nos apontam sintomas daquilo que estamos tentando refutar.

Ocio como "fonte de saude e qualidade de vida"; como "elemento terapeutico"; "parte importante do processo de socialização e dedesenvolvimento comunitario, regional e nacional", são alguns aspectos destacados por Cabeza(1995) e que o levam a diferenciar entre um Ocio positivo e um negativo.

O primeiro seria "verdadeiramente Ocio", relacionado com o descanso, o jogo, a relação com a natureza, a criatividade. Já o segundo, é classificado como "ociosidade", é largamente condenado pois está ligado às práticas condenáveis e "daninhas" do consumo de álcool e drogas, do "não fazer nada", do sedentarismo, enfim, de todas aquelas práticas condenadas, coincidentemente, pela sociedade do trabalho.

Essa aproximação não nos parece tão casual, afinal, para o autor, apesar de considerar a "exclusão intrinseca do Ocio em relação ao trabalho":

Trabalho e Ocio, em qualquer de suas dimensões, convivem num sentido unitario, em uma mesma vida. $\mathrm{O}$ descanso sem diversão conduz à monotonia, ao aborrecimento e ao tédio...O Ocio se converte em desenvolvimento humano quando se tem clara a idéia do sentido e o valor, isso é o que justificaria a aparição do festivo (historicamente unido ao culto), o criativo (relacionado com um odelo de perfeição) e o solidário (que trata de fazer realidade uma sociedade mais justa).(CABEZA, 1995, p. 35)

\footnotetext{
${ }^{12}$ No inglês, a palavra ócio aparece traduzida como "leisure". Portanto aqui não se trata de uma discussão conceitual sobre ócio e lazer, importante para alguns estudiosos sobre o tema, mas simplesmente uma tradução da palavra.
} 
Mas, se o Ocio é uma atitude "autônoma" como não cansa de afirmar o autor, como posso prescrever, a priori, toda essa responsabilidade para o homem ocioso? Quem decide o que é um Ocio bom e um mau?

Não se trata aqui de optar por uma ou outra "tábua" de valores, mas o que nos preocupa é que impregnar o Ocio com valores religiosos e aproximá-lo unitariamente do trabalho não é também negar a sua própria condição de autodeterminação?

Depois de todo esse percurso, chegamos à algumas conclusões, que obviamente contaram com a ajuda de tantas pessoas, mas que procuraremos sintetizar aqui.

Se o trabalho é para todos, o ócio não. Como demonstra De Grazia (1966), em nenhum momento da história da humanidade todos os seres humanos tiveram ou buscaram o ócio. Em nossa sociedade do trabalho, menos ainda. Não a buscaram seus grandes construtores, nem tampouco seus muitos revolucionários. Mesmo nesse momento em que, mais uma vez afirmamos, a lógica da liberdade poderia se instituir, as pessoas se aprisionam no "mais trabalho", ou num "tempo livre" heterônomo, recheado de recreacionistas, ou de "coisas para fazer" ${ }^{13}$ " que os conduzem pelos campos do consumo administrado.

Apenas alguns poucos, famosos e anônimos, que muito mais do que buscar instalar socialmente uma sociedade do ócio, viveram $e$ vivem suas vidas nesse estado, mesmo nas mais fortes correntes que a sociedade os colocou. A esses dirigem-se a inveja, a admiração e o desprezo, nunca a naturalidade.

Um segundo ponto a destacar é que a reivindicação do ócio é uma tarefa política. "Se o homem tem ócio somente quando é livre, o bom Estado deve existir para dar ócio." (DE GRAZIA, 1966, p. 19)

Como lembra esse autor, ócio e política só se separaram na modernidade e isso devido a ascenção dos interesses comerciais e industriais da nova classe, que trouxe com ela o pressuposto do trabalho como valor positivo. Pior, já ao nosso ver, é que os explorados nessa nova ordem, ao se inserirem nessa nova sociedade,

\footnotetext{
${ }^{13}$ Note-se a cara de "descaso" ou pena, quando ao retornarmos aos nossos locais de trabalho às segundas feiras afirmamos, quando indagados, que não fizemos nada no final de semana.
} 
autoreferenciando-se como "trabalhadores", caíram nos laços com os quais buscavam romper, não conseguindo sair até hoje, ao ponto que aos sindicatos hoje restou apenas manter e atenuar a ordem capitalista, lutando por mais empregos $e$ melhores condições de trabalho, quando muito.

De Grazia (1966, p. 326) ainda nos chama a atenção para o fato de que, na sociedade contemporânea, quando se impõe a lógica do trabalho e do tempo livre, as pessoas cada vez mais se afastam da política. E vai mais além, afirmando que "é impossível dar o passo do tempo livre ao ócio sem sair-se dos limites do credo democrático de hoje, sobre tudo de suas idéias de trabalho e igualdade."

O ócio é uma forma de vida reservada a uma elite, não econômica, como no capitalismo, mas de um grupo de pessoas que constroem sua vida a partir de novos valores, para ele,

O mundo está dividido em duas classes, não três ou cinco ou vinte. Exatamente, duas. Uma é a grande maioria; a outra é a ociosa, não a dos ricos ou os herdeiros, mas daqueles que amam as idéias e a imaginação. Entre toda a massa humana há uns poucos benzidos ou atormentados por esse amor. Podem trabalhar, ou roubar, ou coquetear, ou lutar como todo os demais, porém tudo aquilo que façam estará tocado pelo fogo do pensamento. Podem ser científicos em um século, teólogos em outro, em outro bardos, qualquer que seja a categoria que lhes garantisse a liberdade de deixar jogar com sua mentes. São esses que inventam histórias, criam cosmos, descobrem quanta verdade pode descobrir o humano e a ele lhe dão a melhor parte de sua verdade e de seu erro. Neste seleto mundinho de pensadores, artistas e músicos - não necessariamente em relação a uns com os outros - o que acha sua felicidade naquilo que faz, o que não pode fazer nenhuma outra coisa que seu gênio não o permitirá...Os outros têm sua cultura de massas, ou popular, ou seu folclore; a classe ociosa cria a cultura. Esta cultura não faz necessariamente mais feliz às pessoas que a cultura popular, porém é mais profunda, mais verdadeira, artística, bela. Os da classe não ociosa estão formados por outros. $\mathrm{O}$ da classe ociosa, seja pobre ou rico, nobre ou plebeu, dos fortes ou dos débeis, tem sempre o poder de ser o único que, devido a seu gênio, se forma a si mesmo. (DE GRAZIA, 1966, p. 334)

Nessa constatação, a cultura do ócio instaura o questionamento da ordem estabelecida, de maneira a propor novas possibilidades de viver. $\mathrm{O}$ que se constitui é uma liberdade radical que possibilita aos sujeitos constituírem a sua vida como "uma obra de arte". Isso, segundo De Grazia, vai de encontro à democracia moderna, pois ela também é fruto dessa sociedade. Não cabe mais ser cerceado pelo gosto, pelos hábitos e pelo modo de vida das massas, pois esses são 
constituídos heteronomamente, numa igualdade amorfa, onde se torna condenável a diferença autônoma.

Na educação, como vimos, isso não foi diferente, pois chegamos ao ponto em que:

as escolas, com exceção dessas poucas universidades mais antigas, trabalham eficazmente para negar a tradição do ócio. Suponhamos que na próxima geração todos vão à universidade. Empregarão por isso seu tempo livre de forma diferente da descrita pelo ideal de tempo livre contemporâneo? (DE GRAZIA, 1966, p. 315)

Pelo que verificamos, seríamos ainda mais pessimistas que ele, nem as "universidades mais antigas", que no caso brasileiro não significa muito tempo, são mais exceções. Talvez alguns departamentos, alguns professores e professoras que insistentemente acreditam numa outra educação que não a que se apresenta hoje.

Para nós, a grande diferença estaria na aposta entre uma educação para o trabalho, como hoje se consolida e uma que se arriscasse a pensar noutra direção. Não centrada em grandes projetos governamentais ou mercadológicos, mas numa ação do cotidiano, anárquica, como aprendemos a fazer com grandes professores, professoras, alunos e funcionários com quem convivemos e que desenvolveram essas ações fraternas e culturais na convivência, apesar do mercado, do Banco Mundial, dos governos.

Hoje olhamos para trás, vimos paisagens bonitas, mas impossíveis de serem reerguidas. Assistimos ao nascer desse céu sombrio, aliás, nem o céu podemos ver mais, trancados em nossos afazeres. Seguimos pela vida cotidiana, dentro dessa mísera parcela de realidade, e aprendemos suas imensas dimensões pela dor da perda e pela paixão da convivência. Saímos para respirar e experimentamos o ócio.

Ouçamos Rimbaud (2015, p. 34):

O trabalho humano! é a explosão que ilumina o meu abismo de quando em quando.

"Nada é vaidade; em direção à ciência e para a frente!" exclama o moderno Eclesiastes, isto é, Toda a gente. E todavia os cadáveres dos maus e dos ociosos caem sobre o coração dos outros... Ah! depressa, mais depressa; lá longe, além, muito além da noite, estas recompensas futuras, eternas... escaparemos delas? 
Que posso fazer? Conheço o trabalho; e a ciência é demasiado vagarosa. Que a oração voa e que a luz explode... bem o vejo. É assaz simples e faz calor demais; passarão sem mim. Tenho o meu dever; como muitos, sentir-me-ia orgulhoso pondo-o de lado Está gasta a minha vida. Vamos! finjamos, folguemos, ó piedade! E existiremos enquanto nos divertirmos, a sonhar amores monstruosos e universos fantásticos, enquanto nos lamentarmos e disputarmos contra as aparências do mundo, saltimbanco, mendigo, artista, bandido, - sacerdote! Sobre meu leito de hospital, o cheiro do incenso me fez tão poderoso; guardião dos perfumes sagrados, confessor, mártir...

Reconheço ai a sórdida educação de minha infância. Que importa! Viver meus vinte anos, se mais outros vinte anos eu ainda viver... Não! Não! no momento eu me revolto contra a morte! O trabalho afigura-seme ofensivo demais ao meu orgulho: minha traição ao mundo seria um suplício assaz breve. No derradeiro instante, atacarei à direita, à esquerda...

Então, - oh!. - pobre alma querida, será perdida por nós a eternidade.

\section{REFERÊNCIAS}

CABEZA, Manuel Cuenca. Temas de pedagogia del ocio. Bilbao: Universidade de Deusto, 1995.

DE MASI, Domenico. O ócio criativo. Rio de Janeiro: Sextante, 2000.

DE GRAZIA, Sebastian. Tiempo, trabajo y ócio. Tradução de Consuelo Vazquez de Parga. Madrid: Tecnos, 1966.

HAUSER, Arnold. História social da arte. Tradução de Álvaro Cabral. São Paulo: Martins Fontes, 2000.

LUCCI, Elian Alabi. A educação para o ócio e a criatividade. Disponível em: http://sites.editorasaraiva.com.br/portalgeografia/default.aspx?mn $=184 \& \mathrm{c}=205 \& \mathrm{~s}$ $=0 \&$ friendly=textos-de-apoio. Acesso em 01/10/2015.

MARCUSE, Herbert. Eros e civilização. Tradução de Álvaro Cabral. Rio de Janeiro: Zahar, 1968.

. El arte em la sociedad unidimensional. In: . La sociedad opresora. tradução Ítalo Manzi. Caracas: Tiempo Nuevo, 1970a.

El individuo em la "Gran Sociedad". In: Tradução de Ítalo Manzi. Caracas: Tiempo Nuevo, $\overline{1970 b .}$ . La sociedad opresora. Arte e revolução. In: . Contra-revolução e revolta. Tradução de Álvaro abral. Rio de Janeiro: Zahar, 1973. $\overline{70,1977 .}$

A dimensão estética. Tradução de Maria Elisabete Costa. Lisboa: Edições 
Revista Sul-Americana de Filosofia e Educação - RESAFE

RIMBAUD, Artur. Uma estação no inferno. Disponível em: http://www.dominiopublico.gov.br/download/texto/cv000029.pdf. Acesso em: 01/10/2015.

VANEIGEM, Raul. De la huelga salvaje a la autogestión generalizada. Tradução de Joaquim Jorda. Barcelona: Anagrama, 1978. 